\title{
The Organizational-Economic Mechanism for the Development of Integration Processes in the Production and Processing of Products
}

Submitted 03/02/19, $1^{\text {st }}$ revision $28 / 03 / 19,2^{\text {nd }}$ revision 08/04/19, accepted $15 / 04 / 19$

\author{
O.Yu. Voronkova ${ }^{1}$, V.V. Sorokina ${ }^{2}$, S.V. Baburin ${ }^{3}$
}

\begin{abstract}
:
Purpose: The article considers the development of integration processes in the production and processing of agricultural products.

Design/Methodology/Approach: The competitive development of regional economic complexes requires identifying and implementing new, more efficient forms of production and business activities.

Findings: The development of integration processes in agriculture and processing industry is an important condition affecting the efficiency of economic entities, as well as their organizational, economic and financial sustainability.

Practical implications: The authors suggest an organizational-economic project of the regional integration structure.

Originality/Value: One of the most popular methods for solving the problem of further development of diversified agricultural enterprises is the integration of manufacturers that allows combining the entire reproduction cycle into a single process - starting with the production of raw materials and ending with the release of high-quality products intended for final consumption.
\end{abstract}

Keywords: Integration, cooperation, agribusiness, foodstuffs, quality, control mechanism, project, import substitution.

JEL Classification: $013, Q 1, Q 18, R 58$.

Paper type: Research article.

\footnotetext{
${ }^{1}$ Altai state University, Barnaul, Russia. E-mail: olka2004@yandex.ru

${ }^{2}$ Financial University under the Government of the Russian Federation, Russia.

${ }^{3}$ Saint-Petersburg Mining University, St. Petersburg, Russia.
} 


\section{Introduction}

Agro-industrial integration is an organic association and an effective tool for the functioning of specialized agricultural, industrial and processing enterprises in order to produce final products from agricultural raw materials and achieve the economic benefits of its participants. Due to the mutual material interest of the participants, the agrarian integration became particularly relevant and significant in the second half of the twentieth century, when various organizational forms of integration began to emerge in the form of regional agro-industrial associations, concerns, and agrofirms, based mainly on the administrative method of managing the relations between the participants. The term "agro-industrial integration" was introduced in the 1960-ies as the highest form of integration processes in agriculture (Pinkevich, 2010).

The consequences of the 1998 crisis stimulated a new stage in the creation and development of cooperatives and integrated business structures in the Russian agribusiness. On the one hand, the market cleared for domestic producers, as food imports became unprofitable. On the other hand, the non-payment problems, backward infrastructure, and depreciation of fixed assets promoted investment only in commodity sectors. This created a threat of redirecting production to the more profitable types of non-agricultural activities (Antonov and Ivanova, 2015; Malykh and Gunter, 2016; Jafarpour et al., 2017; Rogatchev and Kuznetsova, 2019).

Russia's accession to the World Trade Organization in 2011, the liberalization of the foreign trade sphere, changes in the geopolitical situation and Russia's role in globalization necessitated fundamental changes in the domestic agricultural sector. Political events in Ukraine in 2014 and the subsequent trade and economic blockade imposed on Russia by foreign countries resulted in more stringent business conditions for most many Russian companies. The level of state support and investment activity of the market participants decreased, the average profitability in agriculture fell below 10\%. At the same time, the costs of agricultural producers associated with seasonal field works and implementation of investment projects have increased by approximately 1.5 times (Plakhina, 2016; Poltarykhin et al., 2018; Voronkova et al., 2018).

\section{Methods}

In the beginning of the last century, the economist Joseph Schumpeter thought that progress in the production of goods is possible only for major subjects of the economic process capable of concentrating a large team of scientists, specialists and developers of new technologies. In his opinion, this superiority will allow major monopolistic companies to force out weaker competitors and the share of small business will decline with the increasing rates of scientific-technical progress. The presented study is based on the study of modern achievements in the field of agro-industrial integration, the development of organizational-economic 
relations between the participants of the integration process. The objectives of this study are ensured using critical analysis of literary sources, general scientific methods - systematic approach, analogy methods, abstract, logical, monographic, statistical and economic methods. Systematic approach served as the methodological basis, which allowed ensuring the comprehensiveness and targeting of the study.

\section{Results}

The primary objectives of integrating agricultural enterprises operating in market conditions are as follows:

- strengthening mutually beneficial economic relations between the subjects of the integration process to increase the effectiveness of the result;

- concentration of all types of resources in the most promising areas;

- using the most optimal payment clearing system,

- improving the quality and competitiveness of products in the domestic and foreign markets,

- reduction of transaction costs,

- more efficient use of production and social infrastructure,

- ensuring a stable position in the market,

- profitability of production-economic activities from a strategic perspective (Shindina, 2017; Sycheva et al., 2017).

Based on these objectives, the agro-industrial integration solves the following objectives: accumulation of financial resources in priority areas of the agriculture development and its service sector, improving the financial conditions of agricultural enterprises, expanding opportunities to promote agricultural products to interregional markets, overcoming local monopolism and forcing out intermediaries from the turnover, employment growth and improving the material lives of the rural population.

Under such features of agriculture as production seasonality (Borvinskaya et al., 2016), impossibility of long-term storage of products, the risk and unpredictability of production results due to the influence of natural and climatic conditions (Nikulin and Epifancev, 2017; Kazantsev and Kochneva, 2017; Kochneva and Kazantsev, 2017; Nikulin and Nikulina, 2017), technical backwardness of the industry, high equipment wear, limited financing sources and investment riskiness, poorly developed market infrastructure in rural areas are the main reasons for agro-industrial integration. Agriculture has a lower investment rating compared to processing and infrastructure sectors (Agafonova, 2015; Khaibullina, 2016; Agibalov and Orekhov, 2013). At the same time, both the government and agribusiness representatives clearly understand that import substitution in agricultural production is not just the policy of national producer support, but also a strategy for 
ensuring food security of Russia, a guarantee of social and economic stability and sustainable development of the country's agrarian regions.

The development of integration processes in agriculture and processing industry is an important condition affecting the efficiency of economic entities, as well as their organizational, economic and financial sustainability. Currently, the formation and development of integrated structures in the domestic agribusiness have all the prerequisites for further globalization and concentration of production. The authors of this study suggested and substantiated a draft of regional integration structure in agribusiness (Figure 1).

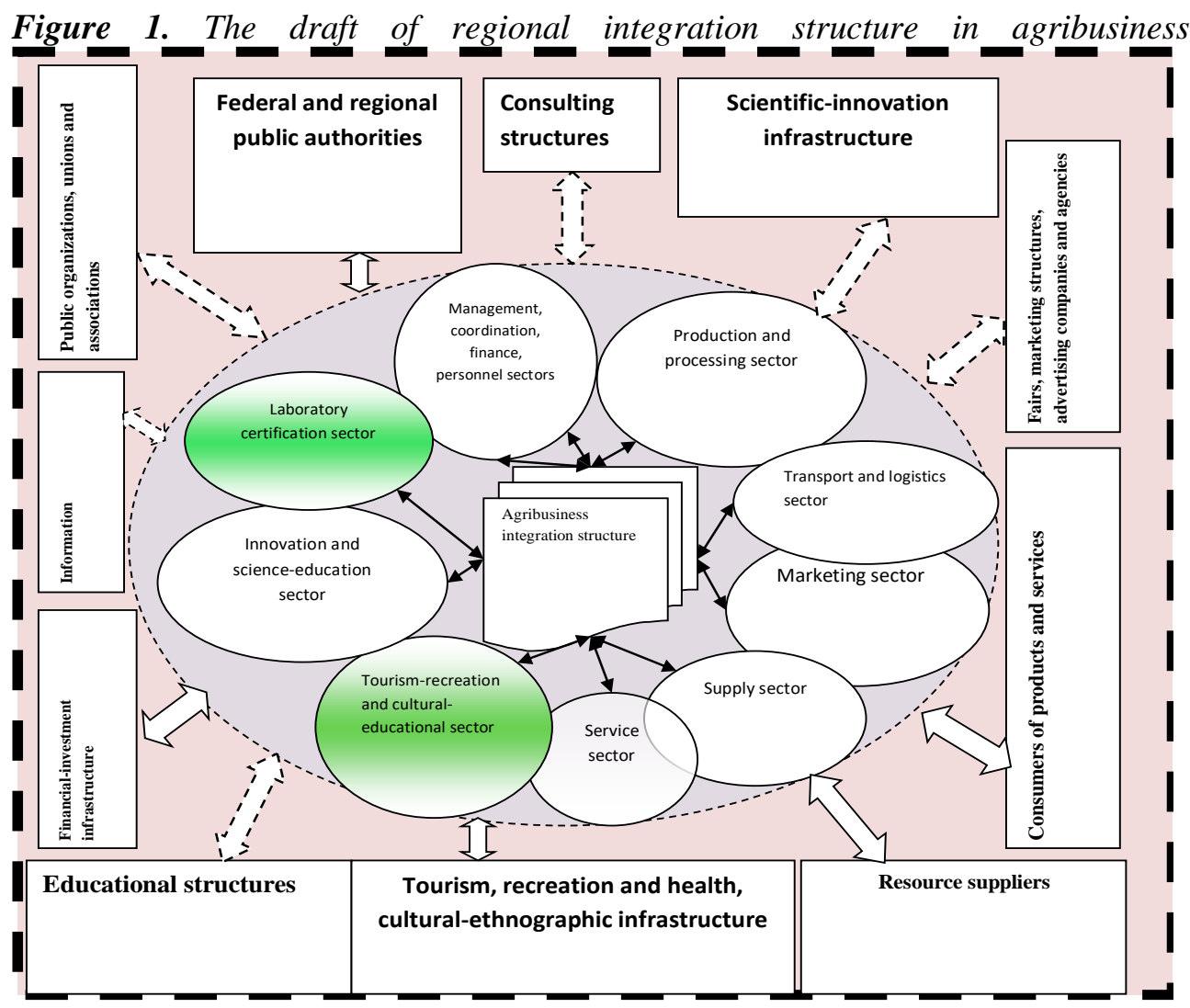

The proposed model of regional integration structure in agribusiness includes the following key sectors: production and processing, supply, transport and logistics, service, marketing sectors. This allows determining an effective chain "productionprocessing-marketing of agricultural products". To improve the efficiency of management and development of additional activities of the regional integration structure, the authors allocated the following sectors: management, coordination, finance, personnel, innovation, science and education. The draft structure proposed the creation of a laboratory-certification sector, as well as the tourism-recreation 
and cultural-educational sectors, which is especially important for agrarian regions with potential in the field of cultural and health tourism (Agamirova et al., 2017). The process of formation and development of integrated agricultural structures has the following prerequisites and conditions (Dankova et al., 2016; Ilyin, 2012):

- the need to use the traditional experience of agriculture and the country's agricultural production system, primarily the experience of collective and state farms during the existence of the Soviet Union;

- comprehensive analysis of the organizational-economic conditions for the development of integration processes in agriculture regarding identifying trends in the development of the economy as a whole;

- formation of specific mechanisms and procedures for the implementation of integration processes - creation and support of economic conditions at all levels and stages of development of agro-industrial integration, including various organizational and legal forms of management;

- developing a regulatory framework for the legal, financial, credit, price and tax regulation of the integration processes.

Having considered the prerequisites, conditions and factors for the formation and development of integrated agricultural structures, it can be argued that, first, the agro-industrial integration plays a significant role in socio-economic development. Secondly, new types, forms and methods of economic activity are developing and forming in changing conditions (Lvov and Aleksandrova, 2016). Finally, for some business entities, the integration process is the only way to retain market positions in the overall market globalization.

Based on the objective nature of deepening social labor division in agriculture and, accordingly, the need to strengthen economic relations, the agribusiness integration is primarily reduced to improving their management efficiency achieved through:

- increasing the scale of production;

- connecting separate stages of one process;

- formation of a complete production cycle, processing, and sales of high-quality agricultural products.

To achieve the objective, agribusiness subjects seek to minimize transaction costs by creating a specific organization. At the same time, when creating a specific institutional and legal form of agro-industrial formation, its participants set themselves various economic, technological (Dashko and Kotiukov, 2017; Lange and Lebedeva, 2019) and organizational tasks. Coordination of management activities within individual enterprises and organizations allows for the consistent implementation of these tasks (Amirova et al., 2018; Lanfranchi et al., 2014). 
Thus, agro-industrial integration is an economically sound and promising form of combining business efforts and resources of enterprises in various industries based on concentration of production, combination of successive stages of processing agricultural raw materials, creating an effective marketing and logistics structure (that allows minimizing transaction costs of production), processing and marketing of finished products. Organizational-economic relations as components of the economic mechanism in integrated formations form a multidimensional structure of the following components:

- organizational structure of interaction. The recent experience suggests that preservation of highly specialized production and improvement of its efficiency are impossible without the formation of a single economic space by creating various organizational forms. Those forms regulate and coordinate the activities of separate production units. An integrated system should ensure the organizational unity of the entire technological process of food production.

- economic foundations of integrated formations. The analysis of disintegration processes in agriculture showed that the main factor of their development was incorrect privatization of enterprises. As a result, the unified technological systems were divided into separate independent enterprises. Their activity is subject to fulfillment of their own interests, which do not coincide with the interests of all participants in the technological process, and sometimes directly oppose those interests.

\section{Conclusion}

Based on the study of theoretical aspects of organizational-economic relations, the authors revealed that their purpose in integrated agro-industrial formations is to create and regulate the organizational structure and economic relations of integration participants on mutually beneficial conditions to substantiate the socioeconomic effect of integrated formations.

Considering the above, the main organizational-economic mechanism of agroindustrial integration is a simultaneous functioning of all its elements and levers: forms and methods of operations management, economic incentives, production organization forms, legal mechanism. For this purpose, it is necessary to adopt several regulatory documents on the implementation of separate economic levers in terms of agricultural production planning, standardization and product quality, regulation of price relations, changes in lending, subsidies, insurance, taxation and other elements that reflect the features of agricultural production functioning.

Thus, the creation of agro-industrial formations is an important element contributing to the adaptation of the market participants. When creating favorable conditions, such organizations may have large scales of production; accumulate enough property, labor and financial resources; create new jobs, use raw and other 
materials more efficiently, maintain a high level of product quality, rapidly implement the results of scientific-technical progress in production.

\section{References:}

Agafonova, I.P. 2015. Ways and problems of vertical integration of Russian enterprises in the modern economy. Management in Russia and abroad, 5, 99-108.

Agamirova, Ek.V., Agamirova, El.V., Lebedeva, O.Ye., Lebedev, K.A., Ilkevich, S.V. 2017. Methodology of estimation of quality of tourist product. Quality - Access to Success, 157, 82-84.

Agibalov, A.V., Orekhov, A.A. 2013. The Concept of optimization of financial resources in integrated structures of agro-industrial complex. Financial Analytics: problems and solutions, 13(151), 47-53.

Amirova, E.F., Voronkova, O.Y., Pyurveeva, K.A., Shatalov, M.A., Panteleeva, T.A. \& Sorokina, O.A. 2018. Functioning of agroindustrial complex in the conditions of digital economy. International Journal of Mechanical Engineering and Technology, 9(12), 586-594.

Antonov, G.D., Ivanova, O.P. 2015. Prerequisites for integration and evolution of integration structures in Russia. Management in Russia and abroad, 5, 8-16.

Borvinskaya, E.V., Sukhovskaya, I.V., Kochneva, A.A., Vasilyeva, O.B., Nazarova, M.A., Smirnov, L.P. \& Nemova, N.N. 2016. Seasonal variability of some biochemical parameters in the whitefish (coregonus muksun and coregonus lavaretus). Contemporary Problems of Ecology, 9(2), 195-202, doi:10.1134/S1995425516020013.

Dankova, L.V., Zolotareva, N.A. Bakutkin, A.S. 2016. Integrated structures in the agricultural economy of the region. Bulletin of Voronezh state agrarian University, 1(48), 207-213.

Dashko, R., Kotiukov, P. 2017. Analysis of construction accident in Saint Petersburg based on consideration of underground space as a contaminated multicomponent system. International Multidisciplinary Scientific GeoConference Surveying Geology and Mining Ecology Management, SGEM, 17 (51), 67-74, DOI: $10.5593 /$ sgem 2017/51/S20.012.

Ilyin, A.I. 2012. The processes of cooperation and integration of business structures in the agricultural sector. Socio-economic phenomena and processes, 1(35), 72-77.

Jafarpour, H., Moghadasi, J., Petrakov, D.G., Litvin, V., Roshchin, P. \& Kuznetsova, A. 2017. Self-diverting emulsified acid for stimulation of iranian ab-teymur carbonate reservoir. Paper presented at the 79th EAGE Conference and Exhibition 2017 Workshops.

Kazantsev, A.I. \& Kochneva, A.A. 2017. Ground of the geodesic control method of deformatons of the land surface when protecting the buildings and structures under the conditions of urban infill. Ecology, Environment and Conservation, 23(2), 876882.

Khaibullina, K. 2016. Technology to remove asphaltene, resin and paraffin deposits in wells using organic solvents. Paper presented at the Proceedings - SPE Annual Technical Conference and Exhibition, 2016-January.

Kochneva, A.A. \& Kazantsev, A.I. 2017. Justification of quality estimation method of creation of digital elevation models according to the data of airborne laser scanning when designing the motor ways. Journal of Industrial Pollution Control, 33(1), 1000-1006. 
Lanfranchi, M., Giannetto, C., De Pascale, A. 2014. The role of nature-based tourism in generating multiplying effects for socio economic development of rural areas. Quality - Access to Success, 140, 96-100.

Lange, I. and Lebedeva, Y. 2019. Engineering-Geological Zoning of the Route of Technological Tunnel Designed Under Complex Structural and Tectonic Conditions, International Journal of Civil Engineering and Technology, 10(04), 341-350.

Lvov, V.V. \& Aleksandrova, T.N. 2016. Automated control of hydrocyclone classification. Gornyi Zhurnal, (5), 94-96, doi:10.17580/gzh.2016.05.14.

Malykh, M.S., Gunter, I.N. 2016. Formation of mechanisms of state regulation of financing of integration processes in the agricultural sector. Bulletin of Belgorod University of cooperation, Economics and law, 3(59), 170-179.

Nikulin, A., Epifancev, K. 2017. Selecting sustainable energetic \& design parameters of a screw extruder for biofuel production. Ecology, Environment and Conservation, 23(2), 1037-1042.

Nikulin, A., Nikulina, A.Y. 2017. Assessment of occupational health and safety effectiveness at a mining company. Ecology, Environment and Conservation, 23(1), 351-355.

Pinkevich, I.K. 2010. Types and features of integration processes in the agro-industrial complex of Russia. Problems of modern economy, 1(33), 56-81.

Plakhina, A.A. 2016. The efficient functioning of the integrated agro-industrial groups in regional agriculture. Bulletin of Voronezh state agrarian University, 1(48), 214221.

Poltarykhin, A.L., Alekseev, A.E., Kudryavtsev, V.V., Makhanova, T.A., Voronkova, O.Yu., Aydinov, H.T. 2018. Prospects for the Development of the Green Economy of Russian Federation. European Research Studies Journal, Volume 21, Issue 4, 470-479.

Rogatchev, M.K. \& Kuznetsova, A.N. 2019. Technology of low-permeable polimictic reservoirs water-flooding with surfactant solutions. Paper presented at the Innovation-Based Development of the Mineral Resources Sector: Challenges and Prospects - 11th Conference of the Russian-German Raw Materials, 161-166.

Shindina, T.A. 2017. The paradigm of a "green" organizational model: new approaches to the quality of life and the evolution of organizational theories. Quality - Access to Success, 160, 156-161.

Sycheva, I.N., Ovchinnikov, Y.L., Permyakova, E.S., Voronkova, O.Yu. 2017. Organic Production at Long-fallow Lands as a Strategic Resource of the Food Import Substitution Policy. Revista Espacios, 38(33), 40.

Voronkova, O.Y., Akhmetshin, E.M., Sycheva, I.N., Shpakova, R.N., Pashkova, E.Y. \& Poltarykhin, A.L. 2018. Economic mechanism of regulating land relations in the agricultural sector of Russia. European Research Studies Journal, 21(4), 280-291. 